
\title{
$\begin{array}{ll}\text { Research Square } & \begin{array}{l}\text { Preprints are preliminary reports that have not undergone peer review. } \\ \text { They should not be considered conclusive, used to inform clinical practice, } \\ \text { or referenced by the media as validated information. }\end{array}\end{array}$
}

\section{Inertial Effects Due to Eruption-induced Atmospheric Disturbances Identified by Superconducting Gravimeter Observations at Matsushiro, Japan}

\section{Yuichi Imanishi ( $\sim$ imanishi@eri.u-tokyo.ac.jp )}

Earthquake Research Institute, The University of Tokyo https://orcid.org/0000-0001-5172-3901

\section{Research Article}

Keywords: gravity, atmosphere, loading, inertial effect, rigidity, atmospheric Lamb wave, Tonga eruption

Posted Date: February 24th, 2022

DOI: https://doi.org/10.21203/rs.3.rs-1379596/v1

License: (9) This work is licensed under a Creative Commons Attribution 4.0 International License. Read Full License

Version of Record: A version of this preprint was published at Earth, Planets and Space on April 18th, 2022. See the published version at https://doi.org/10.1186/s40623-022-01615-4. 


\section{Abstract}

The violent eruption of Hunga Tonga-Hunga Ha'apai volcano on January 15, 2022 induced strong atmospheric disturbances, which traveled around the world as atmospheric Lamb waves. When this wave passed through the superconducting gravimeter station at Matsushiro, Japan, a large signal of gravity changes was recorded. Also, barometers installed around Matsushiro recorded wave trains of pressure changes. Analysis of the barometer data revealed that the atmospheric disturbances traveled as plane waves. Applying the theory of atmospheric loading for traveling plane waves, the observed gravity changes were well reproduced by a sum of three components of atmospheric loading, namely, Newtonian, free-air and inertial effects. In particular, the inertial effect of atmospheric loading, which is rarely observed, is clearly identified in the gravity data. From the theoretical modeling, an estimate of rigidity in the shallow region of the Earth was also obtained.

\section{Introduction}

Atmospheric loading has significant effects on surface gravity observations using highly sensitive instruments such as the superconducting gravimeter (Prothero and Goodkind, 1968; Warburton and Goodkind, 1977; Goodkind, 1999; Hinderer et al., 2007a). Usually, this effect is considered as a combination of the following two agents (Hinderer et al., 2007b). For one thing, a positive change in atmospheric pressure causes larger upward Newtonian attraction by atmospheric mass, resulting in a decrease in gravity (Newtonian effect). For another, a positive change in atmospheric pressure causes downward displacement of the ground, resulting in an increase in the gravity measured on the surface of the Earth (free-air effect). In total, a decrease in gravity is observed for an increase in atmospheric pressure, because the former effect is larger in magnitude. These effects are commonly described using a single factor of proportionality representing the magnitude of a change in gravity acceleration for a unit change in surface atmospheric pressure. This factor, called atmospheric admittance, takes a value close to $-3 \times 10^{-11} \mathrm{~ms}^{-2} \mathrm{~Pa}^{-1}$ (the minus sign means that a positive pressure change causes a negative change in gravity), and varies slightly depending on the location (Hinderer et al., 2007b). Considering the precision of the superconducting gravimeter, this is a really large effect, and many efforts have been made to improve the precision of atmospheric corrections (e.g. Merriam, 1992; Neumeyer, 1995; Crossley et al., 2002; Boy et al., 2002; Neumeyer et al., 2004; Klügel and Wziontek, 2009).

In addition to the Newtonian effect and the free-air effect, Zürn and Wielandt (2007) pointed out, in thier theoretical considerations on the minimum of background seismic spectra in the vertical component, that there should be an inertial effect of atmospheric loading on surface acceleration measurements. Among the several models considered in that paper, they investigated the case of acoustic-gravity waves based on the work by Sorrells (1971), and provide necessary formulae for calculating gravity effects. Because the inertial effect originates from the acceleration of the ground to which the sensors are fixed, it does not show up at zero frequency, and can emerge only at higher frequencies. Although Zürn and Wielandt (2007) did not demonstrate an observational evidence in real records, Zürn and Meurers (2009) showed an example of phase reversal in the atmospheric effects at millihertz band observed by the 
superconducting gravimeter C025 at Vienna, which implies the existence of the inertial effect of atmospheric loading. Although daily variations in the atmosphere have spectral power in such frequency bands, they seldom appear as a clear signature of the inertial effect in the records of gravimeters or seismometers, because such variations are spatially random. Spatially coherent variations in the atmospheric pressure are needed so that the inertial effect of atmospheric loading can be identified by surface gravity or seismic observations.

On January 15, 2022, the Hunga Tonga-Hunga Ha'apai volcano in Tonga erupted violently. This event induced strong disturbances in the atmosphere which propagated around the world as atmospheric waves. The waves are considered to be atmospheric Lamb waves (e.g. Watada, 2009; Arai et al., 2011). The atmospheric Lamb waves are classified into a special branch of propagating waves in the stratified atmosphere, and propagate along the bottom boundary of the atmosphere. The atmospheric Lamb waves are not dispersive, meaning that they do not change waveforms as they travel except for the effect of energy dissipation. After traveling about $8,000 \mathrm{~km}$ from Tonga, the waves passed Japan about 8 hours after the eruption. A local barometer network built around the superconducting gravimeter station at Matsushiro, Japan (Imanishi et al., 1997; Imanishi et al., 2004) recorded wave trains of the pressure signals from this event. The recorded pressure signals were almost identical, indicating that the waves took the form of plane waves and therefore that highly coherent variations in the surface pressure had occurred in this region. Also, gravity changes associated with the passing of atmospheric disturbances were precisely recorded by a superconducting gravimeter at Matsushiro. In this paper, we will show a clear evidence of the inertial effect of atmospheric loading, by analyzing both the gravimeter and barometer recordings. It will be also shown that the same analysis led to rough estimation of rigidity of the Earth.

\section{Characterization Of Atmospheric Disturbances}

We start with characterizing the atmospheric disturbances observed at and around the Matsushiro station (see Fig. 1). At Matsushiro, the superconducting gravimeter iGrav \#028 has been in operation since February 2019. In an effort to improve the precision of atmospheric correction for the superconducting gravimeter, we built a local network of barometer observations around Matsushiro. Four of such barometer stations are still in operation, as shown in Fig. 1 and Table 1. The sampling interval of the barometers is $1 \mathrm{~s}$. 
Table 1

Barometer stations around Matsushiro, Japan.

\begin{tabular}{|llllllll|}
\hline Name & Code & $\begin{array}{l}\text { Latitude } \\
\text { (deg) }\end{array}$ & $\begin{array}{l}\text { Longitude } \\
\text { (deg) }\end{array}$ & $\begin{array}{l}\text { Height } \\
(\mathbf{m})\end{array}$ & Instrument & $\begin{array}{l}\text { Resolution } \\
(\mathrm{Pa})\end{array}$ & Remark \\
\hline Matsushiro & MA & 36.544 & 138.203 & 409.5 & $\begin{array}{l}\text { Paroscientific } \\
6000\end{array}$ & 0.1 & $\begin{array}{l}\text { gravity } \\
\text { station }\end{array}$ \\
\hline Komoro & KM & 36.320 & 138.442 & 742 & $\begin{array}{l}\text { Yokogawa } \\
\text { F4711 }\end{array}$ & 1 & \\
\hline Matsumoto & MM & 36.235 & 138.003 & 653.9 & $\begin{array}{l}\text { Yokogawa } \\
\text { F4711 }\end{array}$ & 1 & $\begin{array}{l}\text { data not } \\
\text { yet } \\
\text { available }\end{array}$ \\
\hline Nagano & NA & 36.668 & 138.183 & 479.7 & $\begin{array}{l}\text { Yokogawa } \\
\text { F4711 }\end{array}$ & 1 & $\begin{array}{l}\text { incorrect } \\
\text { time stamp }\end{array}$ \\
\hline Ohmachi & OH & 36.515 & 137.794 & 825.8 & $\begin{array}{l}\text { Yokogawa } \\
\text { F452 }\end{array}$ & 0.1 & \\
\hline
\end{tabular}

Figure 2 shows the barometer data from the four stations including Matsushiro. We have excluded the Matsumoto station, because the data are not yet available. Since the barometer stations are located at different heights, absolute values of barometric pressure is different from station to station. Aside from the difference in the absolute values and arrival times, it is evident that the barometers at the four stations have recorded very similar wave trains of atmospheric signals from the Tonga volcano. To extract the temporal changes in atmospheric pressure from the volcano, a linear trend was estimated and removed from the data for each station. Extracted signals were subject to calculation of crosscorrelations, from which time difference in arrival times with respect to Matsushiro was estimated. The result was $-115 \mathrm{~s}$ (advance) for Komoro and $+83 \mathrm{~s}$ (delay) for Ohmachi. Here we excluded the Nagano station, because the clock of the recording system there was incorrect at the time of the Tonga event, due to lost connection to internet time servers. We verified that the wave trains of the atmospheric disturbances from the three stations were almost identical if the data from the Komoro and Ohmachi stations were shifted by the estimated time differences.

Given this result, we can conclude that the observed waves propagated as plane waves. The assumption of plane waves will be justified considering the distance (about 8,000 km) from the Tonga volcano and the size (about $100 \mathrm{~km} \times 100 \mathrm{~km}$ ) of our study area. The velocity and azimuth of the waves can be estimated using the difference in arrival times between stations. Figure 3 shows the time difference at each station with respect to Matsushiro, plotted against the distance from the volcano. From this, we obtain $(3.49 \pm 0.01) \mathrm{s} \mathrm{km}^{-1}$ as the slowness of the waves. In other words, propagation velocity of the waves is $(286 \pm 1) \mathrm{ms}^{-1}$. This value is close to, but significantly lower than, $310 \mathrm{~ms}^{-1}$, the value typically quoted as the propagation velocity of the atmospheric Lamb waves (e.g. Nishida et al., 2014). For the present, we identify the observed waves as atmospheric Lamb waves while leaving the reason for the lower velocity unknown. This does not have serious influence on the following analysis of the 
atmospheric loading. The azimuth was estimated to be N45W. This means that the waves came from the south-east direction and traveled to the north-west direction.

\section{Evaluation Of Atmospheric Loading Effects On Gravity}

Since we have collected necessary information on the Lamb waves from the Tonga volcano, now we can calculate each of the three (Newtonian, free-air and inertial) terms of atmospheric loading that would have affected the gravity observed at Matsushiro. For the calculation, we use the data of atmospheric pressure recorded at Matsushiro as representative of the whole study area.

Zürn and Wielandt (2007) gives formulae for calculating the effects of atmospheric loading for several theoretical models. Here we adopt the "acoustic-gravity wave model" (section 4.3) of that paper, because we deal with traveling plane waves. For a single angular frequency $\omega$, the three equations (13), (15) and (16) of Zürn and Wielandt (2007) give the relevant Fourier components of Newtonian, free-air and inertial effects, respectively. Therefore, the necessary steps to be taken here will be (i) Fourier transform the time domain data of surface atmospheric pressure, (ii) multiply the Fourier components by the right-hand sides of the three equations and (iii) inverse Fourier transform the frequency domain data back to the time domain. These procedures are quite simple to implement. However, we found that applying this method to our data gives an unrealistically large value (larger than $0.9 \mu \mathrm{Gal}$ ) for the Newtonian effect. The cause of this phenomenon is likely the assumption of the half-space adopted in the theory. Because the Newtonian attraction slowly decays with distance, a flat Earth model with infinitely wide spatial extension may lead to a serious overestimation of the total force. On the other hand, the free-air and the inertial effects are related with local displacement fields of the ground, which will be affected to a lesser degree by the half-space treatment compared with the Newtonian effect. Therefore, here we choose to adopt a less sophisticated grid-method for calculating the Newtonian effect, whereas the method of Zürn and Wielandt (2007) is applied to calculate the free-air and the inertial effects.

For calculating the Newtonian effect, we consider a square area of $100 \mathrm{~km} \times 100 \mathrm{~km}$ size around Matsushiro (Fig. 1). The whole area is divided by a $360 \times 360$ grid. The size of each cell is about $286 \mathrm{~m}$, corresponding to the propagation length of the Lamb waves in one second (the sampling interval of the barometer data). Within one cell, atmospheric pressure is taken to be uniform. Each cell is further divided into $29 \times 29$ sub-cells, each having the size of about $10 \mathrm{~m}$. Vertically, 10,000 layers with $5 \mathrm{~m}$ spacing are used. The total height of the atmosphere considered is $50 \mathrm{~km}$. It is noted that the atmospheric Lamb waves are evanescent (see Fig. 5 of Arai et al. (2011)). Following Eq. (10) of Zürn and Wielandt (2007), we assume that density perturbations for the traveling waves depends on the height $z$ as $\exp (-z / H \gamma)$, where $H$ is the scale height and $\gamma$ is the specific heat ratio of the atmosphere. We assume that $H=8 \times 10^{6} \mathrm{~m}$ and $\gamma=1.4$. We ignore topography and curvature of the ground. For each epoch, Newtonian attraction due to density perturbations from all the sub-cells is summed up to give the total effect. 
For calculating the free-air and the inertial effects, equations (15) and (16) of Zürn and Wielandt (2007) are applied. We assume that $\lambda=\mu$, where $\lambda$ and $\mu$ are the Lamé constants, so that the factor $(\lambda+2 \mu) /(\lambda+\mu)$ is equal to 1.5 . The vertical gravity gradient $|\delta g / \delta Z|$ is taken to be $3.08 \times 10^{-6} \mathbf{s}^{-2}$ . Note that magnitudes of these two effects are inversely proportional to the value of rigidity $\mu$.

For the observational data of gravity to be compared with theoretical calculations, we apply tidal correction using the parameters determined from more than ten years of gravity observations at Matsushiro. We do not apply the usual atmospheric correction with an admittance ( $-3.3 \times 10^{-11} \mathrm{~ms}^{-2} \mathrm{~Pa}^{-1}$ in the case of Matsushiro). When the atmospheric waves from the Tonga volcano arrived at Matsushiro, the superconducting gravimeter iGrav \#028 was in a normal condition, and there were no irregular behaviors in the temperature or tilt controls of the instrument.

Figure 4(b) shows the calculation results of the three terms of atmospheric loading, using the atmospheric pressure data at Matsushiro shown in Fig. 4(a). The attraction term (blue) looks like a smoothed version of the atmospheric pressure. Because we assume that the atmospheric disturbances take the form of plane waves traveling in one direction, spatially integrating attractions from the cells over the study area is similar in effect to applying a lowpass filter to the time domain data. When the change in atmospheric pressure takes its maximum value of $174 \mathrm{~Pa}$ at 11:37 (UTC), the gravity decrease from the attraction term reaches $7.3 \times 10^{-9} \mathrm{~ms}^{-2}$. If we simply calculate the ratio between these numbers, we obtain $-4.2 \times 10^{-11} \mathrm{~ms}^{-2} \mathrm{~Pa}^{-1}$ as an apparent admittance. The reason why this is larger than usually seen comes from the fact that in the case of Lamb waves the atmospheric admittance due to Newtonian attraction is theoretically about 1.4 times as large (in the absolute sense) as that for the atmosphere in static equilibrium (Zürn and Wielandt, 2007). During the initial positive pressure pulse of the Lamb waves (from 11:18 to 11:46), the negative changes in gravity due to the Newtonian effect are partly cancelled by positive changes due to the free-air (green) and the inertial (red) effects. The rigidity $\mu$ is taken to be $50 \mathrm{GPa}$. The free-air effect is temporally smoother than the inertial effect, because the latter is derived by differentiating the former twice with respect to time for each Fourier component. The sum of the three terms (magenta) is shown in Fig. 4(c). It reproduces well the observed gravity changes (black). The calculation reproduces also the latter parts of the wave train (from 11:50 to 12:30), indicating that our model also fits those later phases of atmospheric waves.

The good agreement between observations and theoretical calculations proves that the theory of Zürn and Wielandt (2007) is correct. In particular, incorporating the inertial effect of atmospheric loading which is often neglected is the key feature to understand the observed gravity signals. In other words, this result may be regarded as a clear identification of the inertial effect of atmospheric loading by surface gravity observations. If we subtract the Newtonian and the free-air terms from the observed gravity, we can isolate the inertial term. Figure 4(d) shows the inertial effect thus extracted, to be compared with the calculated one shown in Fig. 4(b). This is the "signal" of the inertial effect of atmospheric loading, identified by precise gravity observations with a superconducting gravimeter. This identification was made possible because the atmospheric disturbances were (1) energetic enough and (2) spatially coherent. Although this is not the first report of the signal of this kind (Zürn and Meurers, 2009), the 
Tonga event has provided a rare opportunity for studying such a phenomenon with sufficient signal-tonoise ratio.

The rigidity $\mu$ is an undetermined parameter in the theoretical calculations. After some trials, we found that the observation is well explained when we choose $\mu=50 \mathrm{GPa}$, not $40 \mathrm{GPa}$ or $60 \mathrm{GPa}$. In other words, a rough estimate of rigidity has also been obtained from the our analysis (Wang and Tanimoto, 2020). The theory we rely upon in this study was developed on the basis of an elastic half-space with homogeneous elastic properties. Therefore, it is not easy to specify the effective depth to which the present estimate of rigidity is sensitive. Considering that the wavelength of the Lamb waves used in our analysis ranges from a few tens to a few hundreds of kilometers, the estimated rigidity may represent the property in the upper part of the Earth with similar vertical scales. Indeed, rigidity of $50 \mathrm{GPa}$ corresponds to the depth of 30-40 km according to PREM (Dziewonski and Anderson, 1981).

\section{Conclusion}

The atmospheric disturbances induced by the eruption of the Hunga Tonga-Hunga Ha'apai volcano on January 15, 2022 were recorded as clear signals in gravity by the superconducting gravimeter at Matsushiro, Japan. We have successfully modeled the gravity changes by atmospheric loading based on the theory of Zürn and Wielandt (2007). In particular, the inertial effect due to atmospheric loading was clearly identified, almost exactly as predicted by the theory of Zürn and Wielandt (2007).

In addition, analysis of the data has enabled rough estimation of rigidity of the Earth, maybe corresponding to the physical property in the shallow region up to several tens of kilometers depth. From a gravimetric point of view, the Tonga event served as a natural experiment of measuring "how rigid the Earth is" by pressing a wide area of the ground simultaneously while making precise gravity observations on the Earth's surface.

\section{List Of Abbreviations}

No abbreviations.

\section{Declarations}

\section{Ethics approval and consent to participate}

Not applicable.

\section{Consent for publication}

Not applicable.

\section{Availability of data and materials}


The author plan to extend the present investigation to other gravity stations in Japan, in collaboration with other station operators. The data used in this and successive papers will be available upon request, after such works are finished.

\section{Competing interests}

The author declares that he has no competing interests.

\section{Funding}

This work was financially supported by JSPS KAKENHI Grant Number JP21K18644.

\section{Authors' contributions}

YI did all the works.

\section{Acknowledgements}

Gravity observations with a superconducting gravimeter at Matsushiro Seismological Observatory are made in collaboration with Japan Meteorological Agency. Barometer observations at Ohmachi are made possible thanks to the cooperation of the Ohmachi Energy Museum. Komoro and Nagano (Shin'etsu) stations belong to ERI, The University of Tokyo. The author thanks Dr. Shingo Watada (ERI), Dr. Kazunari Nawa (AIST) and Dr. Yosuke Aoki (ERI) for discussion, and Dr. Hiroshi lkeda (KEK) and Mr. Hiroshi Tsuji (ERI) for technical support.

\section{References}

1. Arai N, Iwakuni M, Watada S, Imanishi Y, Murayama T, Nogami M (2011) Atmospheric boundary waves excited by the tsunami generation related to the 2011 great Tohoku-Oki earthquake. Geophys Res Lett 38:L00G18. doi:10.1029/2011GL049146

2. Boy JP, Gegout P, Hinderer J (2002) Reduction of surface gravity data from global atmospheric pressure loading. Geophys J Int 149:534-545. doi:10.1046/j.1365-246X.2002.01667.x

3. Crossley D, Hinderer J, Rosat S (2002) Using the atmosphere-gravity correlation to derive a timedependent admittance. Bull d'Inf Marées Terr 136:10809-10820.

4. Dziewonski AM, Anderson DL (1981) Preliminary reference Earth model. Phys Earth Planet Inter 25:297-356. doi:10.1016/0031-9201(81)90046-7

5. Goodkind JM (1999) The superconducting gravimeter. Rev Sci Instr 70:4131-4152. doi:10.1063/1.1150092

6. Hinderer J, Crossley D, Warburton RJ (2007a) Gravimetric Methods - Superconducting Gravity Meters. In: Schubert G (ed) Treatise of Geophysics, 66-122.

7. Hinderer J, Hector B, Boy JP, Riccardi U, Rosat S, Calvo M, Littel F (2007b) A search for atmospheric effects on gravity at different time and space scales. J Geodyn 80:50-57. 
doi:10.1016/j.jog.2014.02.001

8. Imanishi Y, Segawa J, Furuya I, Kashiwabara S, Takayama H, Nishimae Y (1997) Gravity observation by means of a superconducting gravimeter at Matsushiro, Japan. In: IAG Proceedings "Gravity, Geoid and Marine Geodesy", 115-122.

9. Imanishi Y, Sato T, Higashi T, Sun W, Okubo S (2004) A Network of Superconducting Gravimeters Detects Submicrogal Coseismic Gravity Changes. Science 306:476-478. doi:10.1126/science.1101875

10. Klügel T, Wziontek H (2009) Correcting gravimeters and tiltmeters for atmospheric mass attraction using operational weather models. J Geodyn 48(3-5):204-210. doi:10.1016/j.jog.2009.09.010

11. Merriam JB (1992) Atmospheric pressure and gravity. Geophys J Int 109(3):488-500. doi:10.1111/j.1365-246X.1992.tb00112.x

12. Neumeyer $\mathrm{J}$ (1995) Frequency dependent atmospheric pressure correction on gravity variations by means of cross spectral analysis. Bull d'Inf Marées Terr 122:9212-9220.

13. Neumeyer J, Hagedoorn J, Leitloff J, Schmidt T (2004) Gravity reduction with three-dimensional atmospheric pressure data for precise ground gravity measurements. J Geodyn 38(3-5):437-450. doi:10.1016/j.jog.2004.07.006

14. Nishida K, Kobayashi N, Fukao Y (2014) Background Lamb waves in the Earth's atmosphere. Geophys J Int 196:312-316. doi:10.1093/gji/ggt413

15. Prothero WA, Goodkind JM (1968) A superconducting gravimeter. Rev Sci Instrum 39:1257-1262. doi:10.1063/1.1683645

16. Sorrells GG (1971) A preliminary investigation into the relationship between long-period seismic noise and local fluctuations in the atmospheric pressure field. Geophys J R Astr Soc, 26:71-82. doi:10.1111/J.1365-246X.1971.TB03383.X

17. Wang J, Tanimoto $T$ (2020) Estimating near-surface rigidity from low-frequency noise using collocated pressure and horizontal seismic data. Bull Seis Soc Amer 110(4):1960-1970. doi:10.1785/0120200098

18. Warburton RJ, Goodkind JM (1977) The influence of barometric-pressure variations on gravity. Geophys J R Astr Soc, 48:281-292. doi:10.1111/j.1365-246X.1977.tb03672.x

19. Watada S (2009) Radiation of acoustic and gravity waves and propagation of boundary waves in the stratified fluid from a time-varying bottom boundary. J Fluid Mech, 627:361-377. doi:10.1017/S0022112009005953

20. Zürn W, Wielandt E (2007) On the minimum of vertical seismic noise near $3 \mathrm{mHz}$. Geophys J Int 168:647-658. doi:10.1111/j.1365-246X.2006.03189.x

21. Zürn W, Meurers B (2009) Clear evidence for the sign-reversal of the pressure admittance to gravity near 3 mHz. J Geodyn 48:371-377. doi:10.1016/j.jog.2009.09.040

\section{Figures}




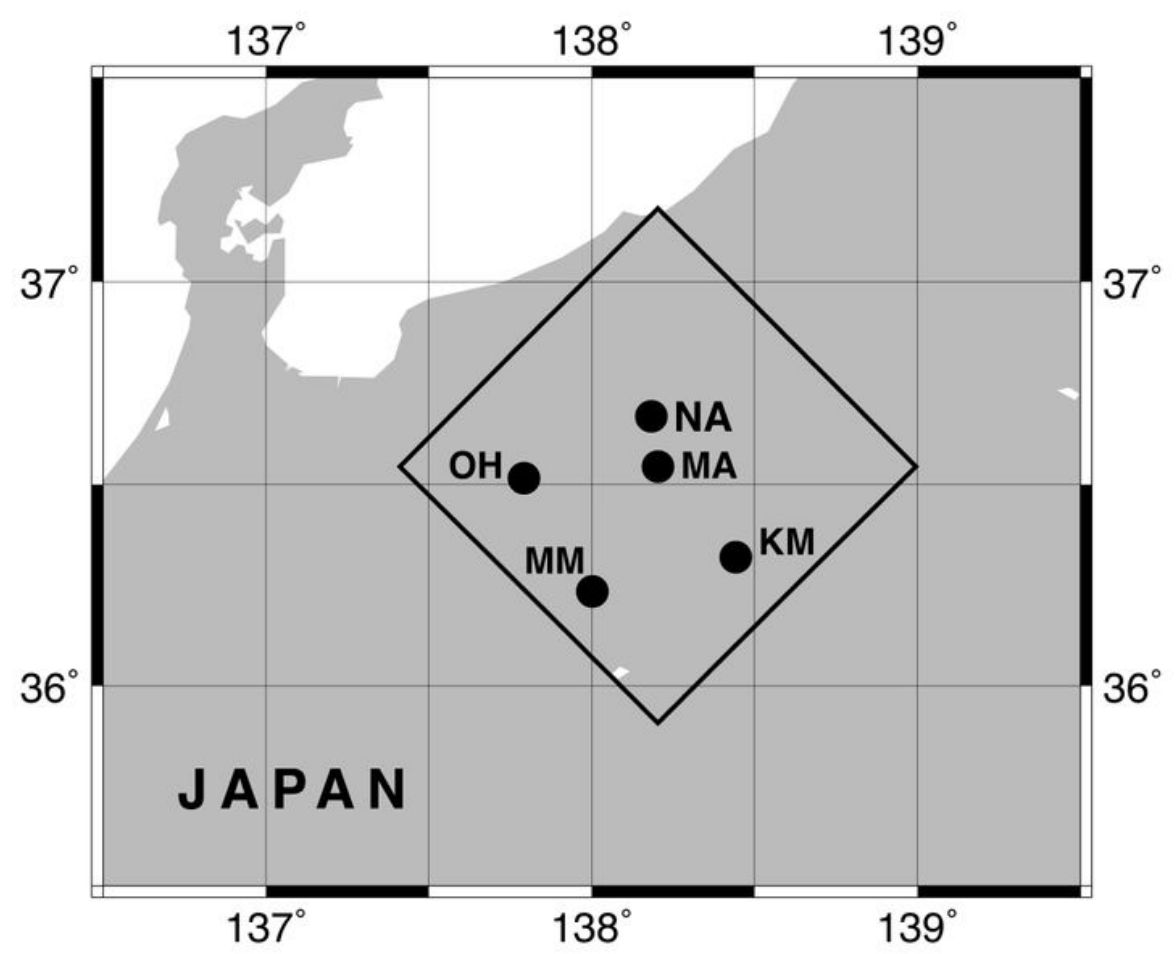

Fig. 1

\section{Figure 1}

Locations of gravimeter and barometer stations used in this study. Station codes represent Matsushiro (MA), Nagano (NA), Komoro (KM), Ohmachi (OH) and Matsumoto (MM). The square indicates the area in which Newtonian attraction by the atmospheric mass is calculated. Atmospheric waves from the Tonga volcano travel from the south-east direction through the north-west direction. 


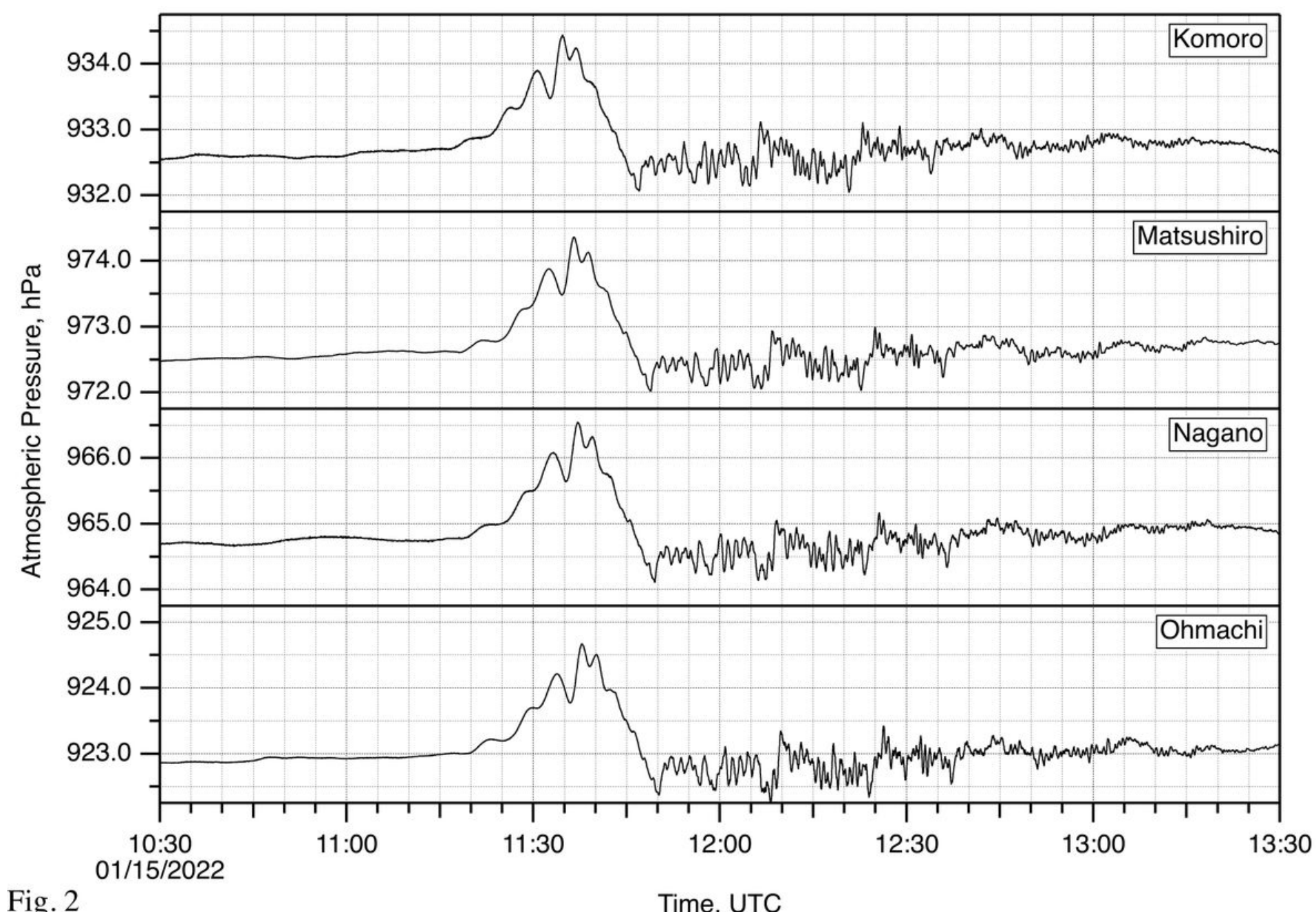

Fig. 2

Time, UTC

Figure 2

Barometer records at the stations around Matsushiro, acquired when the atmospheric waves from the Tonga volcano passed the stations. The data at Nagano shown here have been corrected for the estimated time shift (+677 s) of the data acquisition system. 


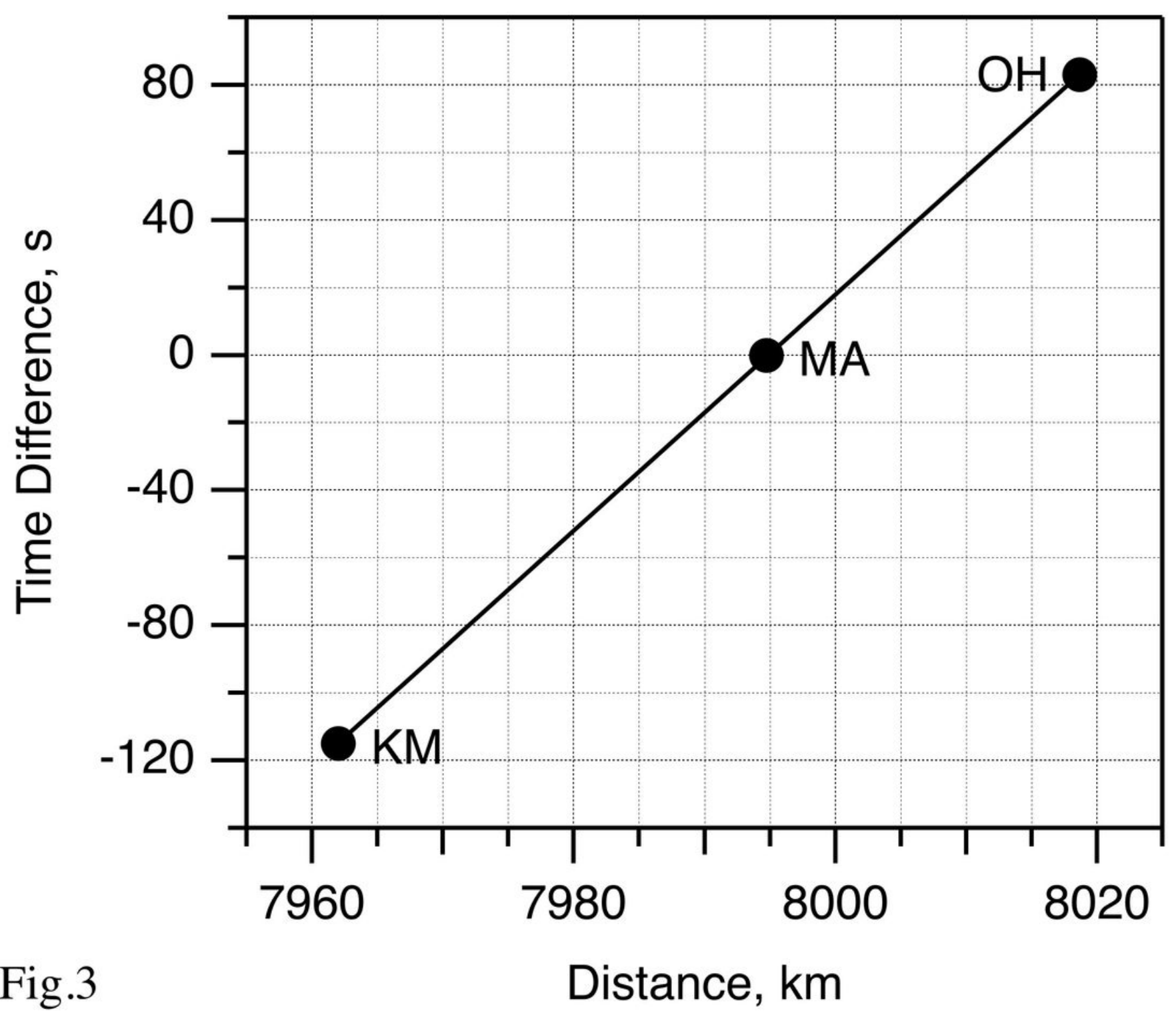

Figure 3

Time difference of pressure wave trains recorded at barometer stations with respect to Matsushiro, as a function of the distance from the Tonga volcano. 


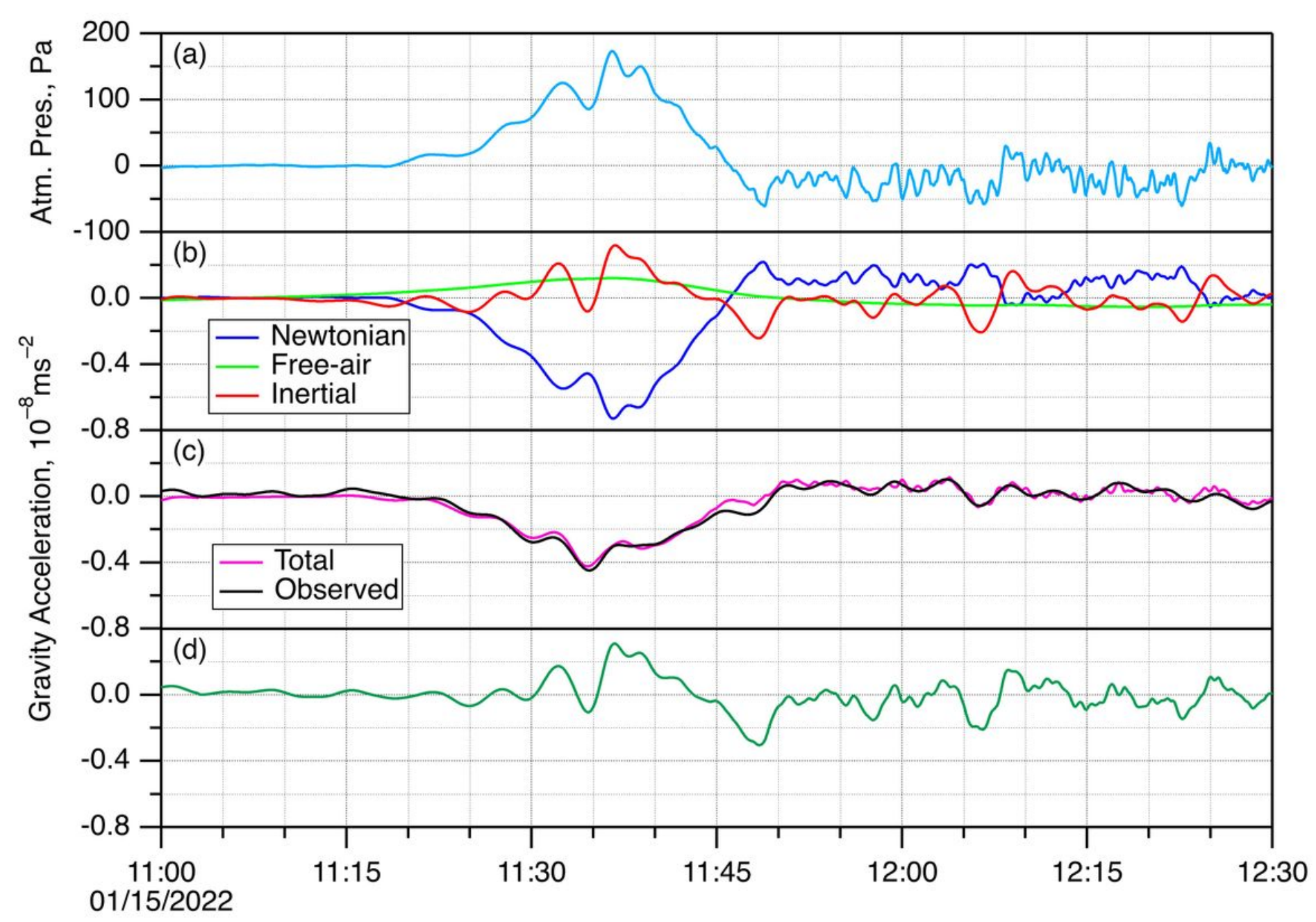

Fig.4

Time, UTC

\section{Figure 4}

(a) Atmospheric pressure changes recorded at Matsushiro. (b) Newtonian (red), free-air (green) and inertial (red) terms of atmospheric loading, calculated using the barometer data shown in (a). (c) Sum of the three terms of atmospheric loading (magenta), compared with the observed gravity changes (black).

(d) The observed gravity changes with the calculated values of Newtonian and free-air effects subtracted.

\section{Supplementary Files}

This is a list of supplementary files associated with this preprint. Click to download.

- GraphicalAbstract3.jpg 